\title{
PERIKANAN TUNA YANG BERBASIS DI KENDARI, SULAWESI TENGGARA
}

\author{
Agustinus Anung Widodo') dan Budi Nugraha²) \\ 1) Peneliti pada Pusat Riset Perikanan Tangkap, Ancol-Jakarta \\ 2) Peneliti pada Balai Riset Perikanan Laut, Muara Baru-Jakarta \\ Teregistrasi I tanggal: 15 Desember 2008; Diterima setelah perbaikan tanggal: 28 Mei 2009; \\ Disetujui terbit tanggal: 17 Juli 2009
}

\begin{abstract}
ABSTRAK
Kendari merupakan salah satu basis perikanan tangkap di Kawasan Timur Indonesia yang berhadapan langsung dengan Laut Banda. Produksi perikanan tuna di Kendari cukup besar, hal ini dikarenakan alat tangkap yang digunakan merupakan alat tangkap yang dikhususkan untuk menangkap ikan tuna, yaitu huhate, pukat cincin mini, dan pancing tonda. Pada bulan April, Agustus, dan Desember 2007 dilakukan penelitian dengan mengambil pengambilan contoh di PPS Kendari. Pengambilan contoh dilakukan secara acak terhadap kapal-kapal yang mendarat pada minggu terakhir bulan April, Agustus, dan Desember. Masing-masing jenis kapal (huhate, pukat cincin mini, dan tonda) diambil satu unit sebagai contoh. Jenis data yang diambil adalah aspek eksploitasi yang meliputi upaya, jumlah, dan jenis hasil tangkapan dan daerah penangkapan. Data lain yang dikumpulkan adalah produksi tuna tahunan dari PPS Kendari. Hasil penelitian menunjukkan bahwa produksi tuna selama 10 terakhir cenderung naik, pada tahun 2007 mencapai 8.381 ton. Daerah operasi penangkapan huhate dan pukat cincin mini meliputi perairan Sulawesi Tenggara dan Sulawesi Tengah, adapun pancing tonda sampai Laut Banda. Rata-rata CPUE huhate rata-rata 6,6 ton/trip, rata-tara CPUE pukat cincin mini 0,9 ton per setting dan rata-rata CPUE pancing tonda 1,3 ton/trip. Penangkapan tuna terjadi sepanjang tahun, puncak musim tahun 2007 terjadi pada bulan September dengan indeks mencapai 0,4 . Jenis tuna yang tertangkap huhate, pukat cincin mini, maupun tonda ada empat, yaitu ikan cakalang (Katsuwonus pelamis), madidihang (Thunnus albacares), tuna mata besar (Thunnus obesus), dan tongkol (Auxis sp.). Komposisi dari keempat jenis tuna tersebut didominansi oleh ikan cakalang yaitu mencapai lebih dari $65 \%$.
\end{abstract}

\section{KATAKUNCI: perikanan tuna, Kendari, Sulawesi Tenggara}

\section{PENDAHULUAN}

Provinsi Sulawesi Tenggara luasnya kurang lebih $153.018,98 \mathrm{~km}^{2}$ terdiri atas wilayah daratan $38.139,98$ $\mathrm{km}^{2}$ dan wilayah perairan laut $114.879,00 \mathrm{~km}^{2}$, mempunyai potensi kelautan dan perikanan yang besar. Potensi tersebut belum sepenuhnya dapat dimanfaatkan dengan baik. Hal ini dapat dilihat pada sumbangan Sub Sektor Kelautan dan Perikanan terhadap Produk Domestik Regional Bruto Sulawesi Tenggara baru 6,17\% (Dinas Kelautan dan Perikanan Provinsi Sulawesi Tenggara, 2003).

Kendari merupakan salah satu basis perikanan tangkap di Kawasan Timur Indonesia yang letaknya berhadapan langsung dengan Laut Banda. Terdapat dua pelabuhan perikanan yaitu Pelabuhan Perikanan Samudera (PPS) Kendari dan Pangkalan Pendaratan Ikan (PPI) Sodohoa. Kedua pelabuhan tersebut merupakan basis perikanan tangkap bagi nelayan skala industri dan tradisional di Kendari.

Sumber daya ikan di perairan Laut Banda dan sekitarnya terdiri atas kelompok-kelompok ikan pelagis besar, pelagis kecil, demersal, moluska dan kerang-kerangan. Sumber daya ikan pelagis besar terutama adalah tuna. Eksploitasi sumber daya tuna dilakukan oleh berbagai bentuk kegiatan perikanan, di antaranya adalah pukat cincin (purse seine), huhate (pole and line), rawai tuna (tuna longline), dan pancing ulur (handline) (Diniah et al., 2001).

Tulisan ini membahas tentang perikanan tuna di Kendari, terkait aspek operasional penangkapan huhate, pukat cincin mini, dan pancing tonda. Selain itu dibahas pula mengenai aktivitas hasil tangkapannya berdasarkan pada data dan informasi yang terkumpul di Kendari, Sulawesi Tenggara.

\section{BAHAN DAN METODE}

Penelitian ini dilakukan dengan basis di PPS Kendari pada Juni, September dan Desember 2007. Jenis data primer berupa aspek ekploitasi perikanan huhate (pole and line), pukat cincin mini (small purse seine), dan tonda (troll line). Data diambil melalui kegiatan pengambilan contoh (sampling) secara acak (random) pada setiap minggu terakhir. Jumlah contoh adalah satu unit dari masing-masing jenis kapal (huhate, pukat cincin mini, dan tonda) yang mendarat pada setiap hari selama minggu terakhir. Jenis data primer meliputi jumlah, komposisi dan ukuran ikan hasil tangkapan, serta upaya (jumlah operasi penangkapan) dan daerah penangkapan. Data 
sekunder adalah berasal dari Laporan Bulanan PPS Kendari, jenis data yang dikumpulkan adalah produksi ikan tuna yang didaratkan di PPS Kendari selama 10 tahun terakhir. Data dianalisis secara deskriptif dan disajikan dalam bentuk grafikal. Musim penangkapan ikan dianalisis dengan perhitungan indeks musim penangkapan selama 10 tahun.

\section{HASIL DAN BAHASAN}

\section{Armada Penangkanan}

Armada atau kapal perikanan yang masuk di PPS Kendari pada umumnya bertujuan melakukan kegiatan pembongkaran ikan, mengisi perbekalan melaut, perbaikan mesin dan alat tangkap serta beristirahat menunggu musim penangkapan. Jenis kapal yang berkunjung ke PPS Kendari, di antaranya adalah kapal huhate, pukat cincin, pukat udang (shrimp trawl), kapal pengangkut (carrier vessel), dan lain-lain. Ukuran kapal mulai dari $<5$ GT sampai $>1.000$ GT. Kapal penangkap tuna yang berkunjung ke PPS Kendari pada umumnya mempunyai ukuran antara <5-100 GT (Tabel 1).

Sebelumnya kapal-kapal huhate, pukat cincin, dan tonda melakukan aktivitas pendaratan hasil tangkapnnya di PPI Sodoha, saat ini sudah banyak yang berpindah ke PPS Kendari. Hal ini dikarenakan pemilik-pemilik kapal pancing tonda sudah melakukan kerja sama dengan perusahaan-perusahaan yang berada di kawasan PPS Kendari untuk melakukan jual beli hasil tangkapan.

\section{Produksi}

Berdasarkan pada Laporan Tahunan PPS Kendari (2008) diketahui bahwa volume pendaratan ikan secara umum di PPS Kendari pada tahun 2007 tercatat 33.198,204 ton, meningkat tajam bila dibandingkan volume pendaratan pada tahun 2006 yang hanya $9.789,892$ ton (Gambar 1 ). Tingginya produksi ikan pada tahun 2007 disebabkan oleh kondusifnya iklim berusaha di Provinsi Sulawesi Tenggara pada umumnya dan PPS Kendari khususnya. Iklim usaha yang kondusif dimaksudkan bertambahnya beberapa perusahaan cold storage yang beroperasi di kawasan PPS Kendari serta bertambahnya armada penangkapan ikan yang datang dari daerah lain dan tumbuhnya pasar ikan dalam skala kecil juga merupakan faktor naiknya produksi ikan pelagis besar yang didaratkan di PPS Kendari.

Produksi perikanan tuna yang didaratkan di PPS Kendari pada tahun 2007 cukup besar yaitu mencapai $8.381,404$ ton atau $25,25 \%$ dari total produksi

Tabel 1. Jumlah kapal ikan berdasarkan pada jenis alat tangkap yang berkunjung ke PPS Kendari, tahun 2007.

\begin{tabular}{cccccccc}
\hline \multirow{2}{*}{$\begin{array}{c}\text { Ukuran kapal } \\
\text { (GT) }\end{array}$} & Huhate & Pukat cincin & Pancing tonda & Ukuran kapal & \multicolumn{3}{c}{ Jenis kapal } \\
\cline { 2 - 7 } & (GT) & Huhate & Pukat cincin & $\begin{array}{c}\text { Pancing } \\
\text { tonda }\end{array}$ \\
\hline$<5$ & - & 33 & 37 & $20-30$ & 22 & 40 & - \\
$5-10$ & 1 & 194 & 143 & $30-50$ & 13 & 4 & - \\
$11-20$ & 2 & 10 & - & & & \\
$20-30$ & 22 & 40 & - & & & \\
$30-50$ & 13 & 4 & - & & & & \\
\hline
\end{tabular}

Sumber: PPS Kendari (2007)

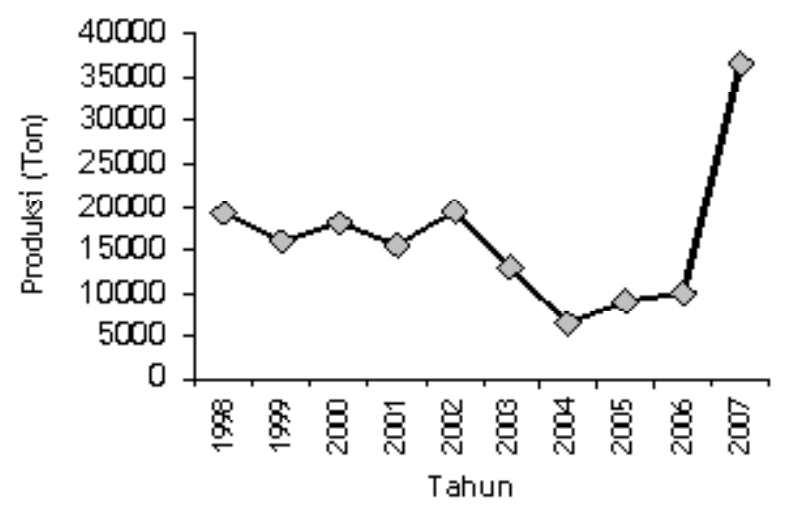

Gambar 1. Fluktuasi produksi tuna yang didaratkan di PPS Kendari, tahun 1998-2007 
perikanan secara keseluruhan. Jenis ikan tuna yang paling banyak didaratkan adalah ikan cakalang, tongkol, madidihang, dan tuna mata besar. Pada Gambar 2 dapat dilihat produksi empat jenis ikan tuna yang didaratkan di PPS Kendari pada tahun 2007.

\section{Musim Penangkapan}

Informasi mengenai musim diperoleh dengan cara mencari rata-rata data bulanan (produksi dan upaya) selama 10 tahun. Nilai tertinggi dari hasil tersebut dijadikan dugaan sebagai bulan-bulan penangkapan, sedangkan nilai terendah merupakan bukan musim penangkapan atau musim paceklik (Merta et al., 2004).

Berdasarkan pada data produksi bulanan hasil tangkapan ikan yang didaratkan di PPS Kendari selama kurun waktu 10 tahun (tahun 1998-2007) dapat digunakan untuk memprediksi musim penangkapan ikan dengan mengetahui perhitungan indeks musim penangkapan selama 10 tahun. Grafik indeks musim penangkapan dapat dilihat pada Gambar 3.

Dari Gambar 3 terlihat bahwa musim penangkapan terjadi pada bulan Januari-Maret dan SeptemberNopember. Puncak musim penangkapan terjadi pada bulan September, sedangkan musim paceklik terjadi pada bulan April-Agustus. Musim paceklik terjadi dikarenakan banyak nelayan yang tidak melaut. Hal ini disebabkan kondisi perairan yang tidak memungkinkan nelayan untuk ke laut karena gelombang dan angin yang besar. Dengan keadaan demikian, jumlah hasil tangkapan yang didaratkan berkurang.

\section{Jenis Perikanan Utama}

Terdapat tiga jenis perikanan yang sangat penting yang mengekploitasi sumber daya ikan tuna dan mendaratkannya di PPS Kendari. Ketiga perikanan tersebut adalah huhate (pole and line), pukat cincin mini atau gae (small purse seine), dan tonda (trolling).

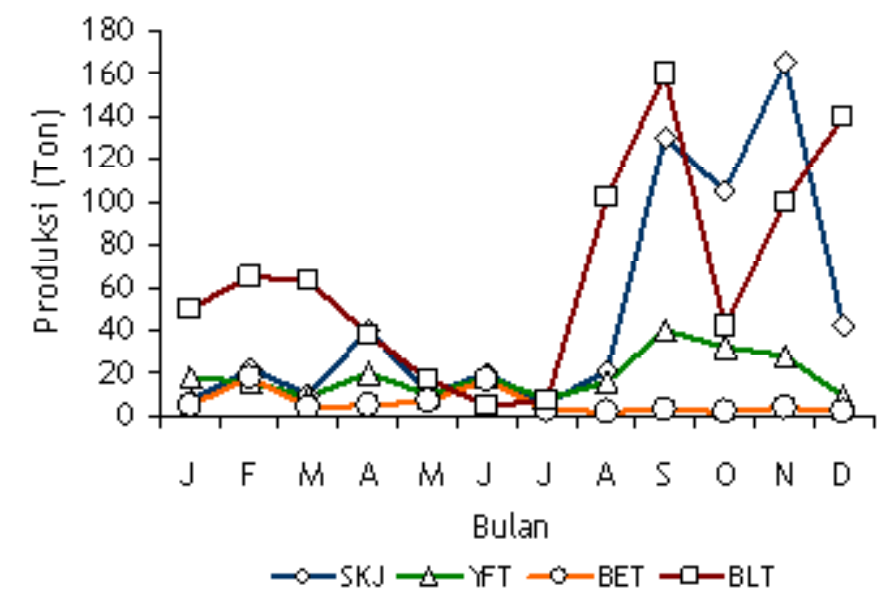

Gambar 2. Produksi ikan tuna (ikan cakalang, madidihang, tuna mata besar, dan tongkol) yang didaratkan di PPS Kendari, tahun 2007.

Keterangan: SKJ (cakalang); YFT (madidihang); BET (tuna mata besar ); BLT (tongkol)

Indek Musim Penangkapan Tuna

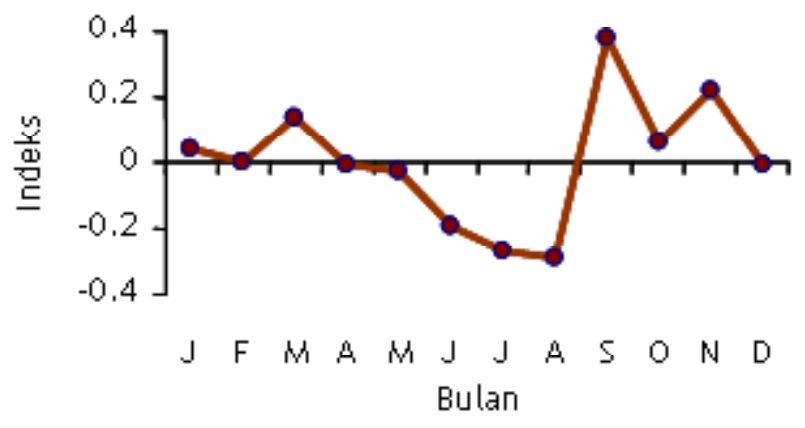

Gambar 3. Grafik indeks musim penangkapan di PPS Kendari. 


\section{Huhate}

Huhate atau pole and line adalah alat tangkap tradisional yang terdiri atas joran atau (pole) dari bahan bambu, tali pancing (line) dari bahan monofilament, dan mata pancing (hook) (Sainsbury, 1996). Terdapat beberapa keunikan dari alat tangkap huhate yaitu, 1) bentuk mata pancing yang tidak berkait dan ditutupi bulu-bulu ayam atau potongan rafia yang halus agar tidak tampak oleh ikan, 2) bagian haluan kapal huhate mempunyai konstruksi khusus, dimodifikasi menjadi lebih panjang, sehingga dapat dijadikan tempat duduk oleh pemancing, 3) pada dinding bagian lambung kapal, di bawah dek, terdapat water sprayer (penyemprot air), dan 4) kapal huhate dilengkapi palkah tempat ikan umpan hidup. Tali utama dan tali cabang pancing huhate yang digunakan oleh nelayan Kendari terbuat dari PE (monofilament) no.2 dengan panjang 1,64 m, sedangkan tali cabang mempunyai panjang $10-16 \mathrm{~cm}$. Joran atau bambu yang digunakan berukuran panjang 2,8-3,8 $\mathrm{m}$. Joran yang dibawa setiap kapal berjumlah 20-30 buah. Mata pancing yang digunakan adalah mata pancing tak berkait dengan panjang $4-5 \mathrm{~cm}$ dan lebar $2 \mathrm{~cm}$.

Kapal huhate yang berbasis di PPS Kendari terbuat dari kayu dan mempunyai ukuran panjang $x$ lebar $x$ dalam (pxlxd) antara 16,85x3,95x1,80 m20,51x4,52x1,70 m dengan tonase antara 28-34 GT. Mesin utama adalah mesin diesel yang mempunyai kekuatan antara 120-160 PK. Mesin bantu pada umumnya berupa mesin berbahan bakar bensin dengan kekuatan 5,5-15 PK. Palkah terdiri atas dua jenis, yaitu palkah untuk menyimpan ikan dan palkah umpan hidup. Palkah penyimpan ikan berjumlah dua buah dengan volume antara 1.500-2.500 kg. Palkah umpan hidup berjumlah dua buah dengan kapasitas 20 ember $( \pm 500 \mathrm{~kg})$ dan terletak di bagian tengah. Anak buah kapal berjumlah 14-15 orang yang terbagi dalam tujuh jabatan utama yaitu nakhoda, kepala kamar mesin, boy-boy (pelempar umpan hidup), pemancing (pemancing andalan pertama, pemancing andalan kedua, dan pemancing biasa), dan koki.

Waktu operasi penangkapan huhate dimulai pagi hari pada pukul 06.30 dan berakhir pada pukul 10.30. Sebelum menuju daerah penangkapan nelayan huhate terlebih dahulu mencari umpan hidup dengan cara membeli kepada nelayan bagan (lift net) dan jaring lingkar. Jenis ikan umpan hidup adalah ikan malalugis atau layang (Decapterus spp.), teri (Stolephorus spp.), dan lemuru (Sardinella spp.) Umpan hidup yang digunakan berjumlah antara 54,2-101,2 kg per setting dengan ukuran panjang (FL) sekitar $5-11 \mathrm{~cm}$. Huhate pada umumnya beroperasi di sekitar rumpon (FADs).
Setelah sampai di daerah penangkapan, boy-boy melemparkan umpan dibarengi dengan semprotan air yang bertujuan untuk mengelabui penglihatan ikan. Sebelum memulai pemancingan, pemancing sudah berada di posisi masing-masing di bagian buritan kapal dengan menggunakan umpan palsu dan mata pancing yang tak berkait. Pemancing yang sudah mahir (pemancing andalan) berada di bagian depan tempat pemancingan, sedangkan yang belum mahir berada di samping kiri dan kanan tempat pemancingan. Setelah selesai melakukan operasi penangkapan, hasil tangkapan disimpan di dalam palkah. Untuk kapal milik perusahaan atau yang bekerjasama dengan perusahaan, jika palkah sudah penuh, kapal huhate akan menuju ke kapal penampung untuk melakukan transhipment dan dibawa ke perusahaan yang berada di PPS Kendari. Metode ini dilakukan untuk menghemat biaya operasional karena kapal penangkap tidak perlu kembali ke pangkalan. Semua perbekalan (logistik) yaitu bahan bakar minyak, es, makanan, dan lain-lain dibawa oleh kapal penampung.

Hasil per upaya penangkapan catch per unit effort huhate berfluktuasi dan mengalami kenaikan yang sangat signifikan pada bulan Oktober. Kenaikan ini dikarenakan produksi meningkat, tetapi upaya penangkapan menurun. Peningkatan produksi dimulai pada bulan September-Desember dikarenakan pada bulan-bulan tersebut merupakan musim penangkapan di sekitar perairan Laut Banda. Penurunan nilai CPUE huhate terjadi pada bulan Nopember dan Desember. Penurunan ini dikarenakan pada bulan Nopember terjadi penambahan upaya penangkapan, sedangkan pada bulan Desember produksi dan upaya penangkapan menurun (Gambar 4).

Daerah penangkapan (fishing ground) nelayan huhate yang berbasis di PPS Kendari berada di sekitar perairan Laut Banda, yaitu di sekitar Pulau Wowoni, Pulau Manui, Pulau Sanua, dan Pulau Tomogolomo (Gambar 5).

Jenis ikan tuna hasil tangkapan tuna kapal huhate di Kendari meliputi ikan cakalang atau skipjack-SKJ, madidihang atau yelowfin tuna-YFT, dan tuna mata besar atau bigeye tuna-BET. Komposisi hasil tangkapan huhate dapat dilihat pada Gambar 6.

\section{Pukat cincin mini (gae)}

Pukat cincin yang dioperasikan nelayan Kendari umumnya berukuran kecil atau mini purse seine atau dikenal dengan nama lokal 'gae'. Pukat cincin termauk dalam katagori jaring dengan bentuk umum empat persegi panjang. Bagian bawah jaring dapat 


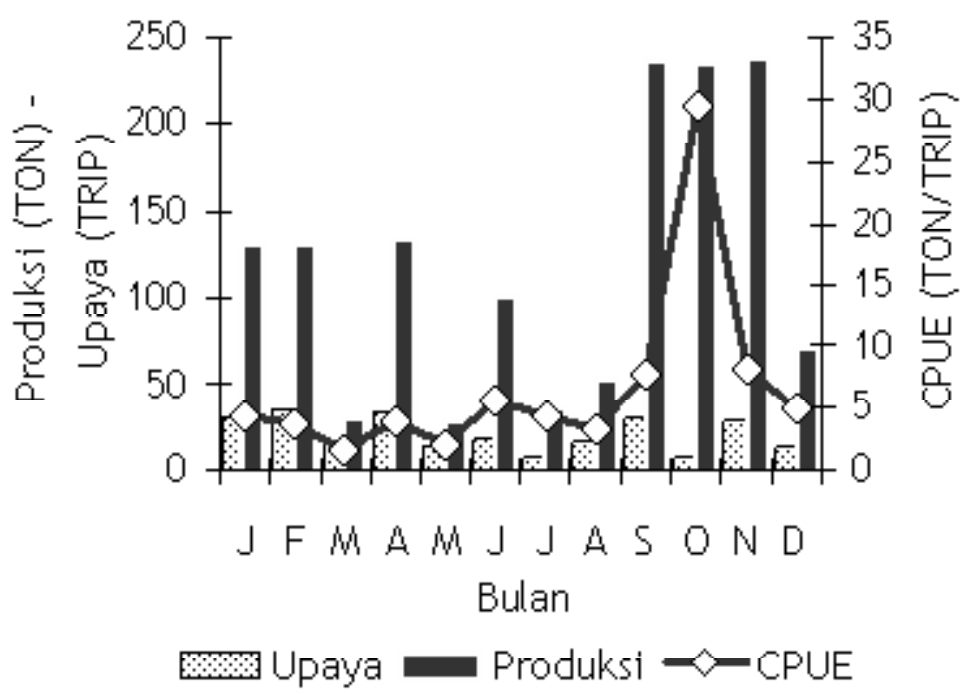

Gambar 4. Fluktuasi upaya penangkapan (trip), produksi tuna (ton) dan CPUE (ton/trip) unit penangkapan huhate di PPS Kendari, tahun 2007.

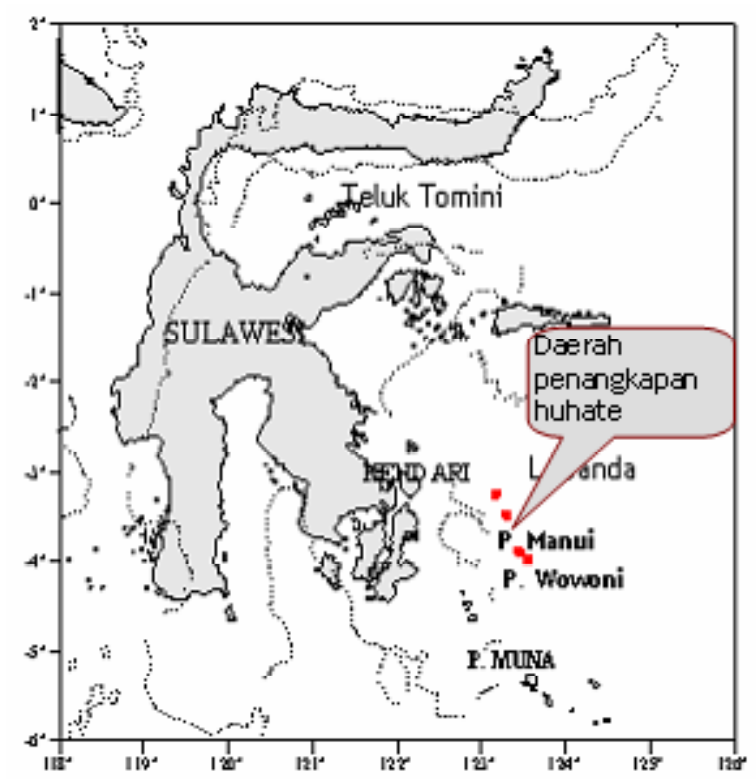

Gambar 5. Daerah penangkapan nelayan huhate yang mendaratkan hasil tangkapannya di PPS Kendari di sekitar Pulau Manuai dan Pulau Wowoni.
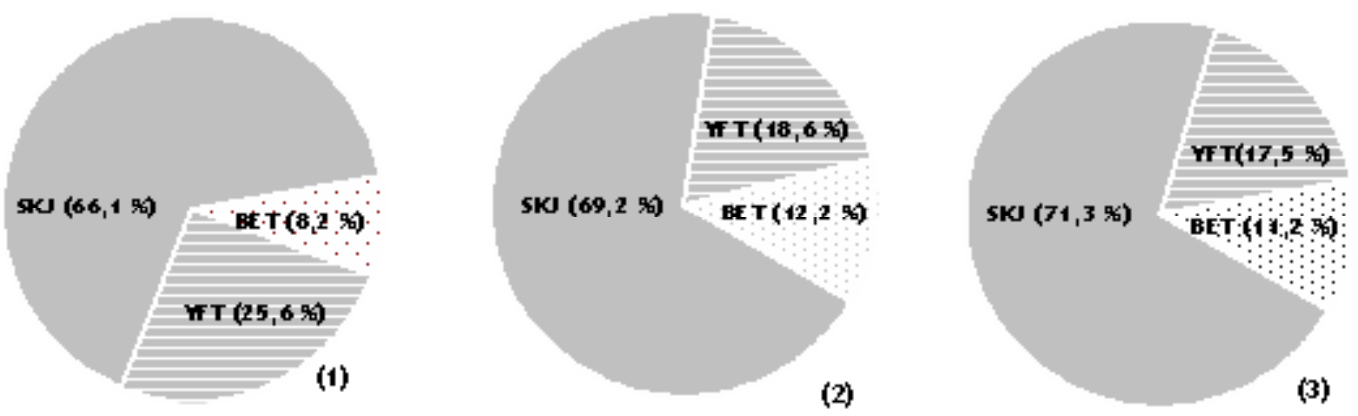

Gambar 6. Komposisi hasil tangkapan huhate bulan Juni, September, dan Desember 2007. 
dikerut hingga membentuk seperti mangkuk saat dioperasikan (Von , 2005). Pukat cincin dioperasikan dengan melingkarkan jaring pada gerombolan ikan (fish schooling) baik yang bergerak bebas atau berada disekirat rumpon (FADs). Konstruksi alat tangkap pukat cincin mini yang digunakan nelayan Kendari pada umumnya setiap unit terbagi dalam 5 bagian utama yaitu, 1) bagian sayap bahan nilon 210/d, $6,1 "=18$ pis $(400 \times 3.622) \mathrm{mata} / \mathrm{pis}, 2)$ bagian bago (tengah) bahan nilon $210 / \mathrm{d}, 9,1 "=8$ pis $(400 \times 3.622)$ mata/pis, 3) bagian kantong bahan nilon 210/d, $12,1 "=4$ pis (400×3.622) mata/pis, 4) bagian selvedge atas bahan PE d.12, 1,5"=12 mata ke bawah, dan 5) bagian selvedge bawah bahan PE d.12, 1,5"=11 mata ke atas.

Tali-temali terbuat dari PE 8, 10, 12, dan $18 \mathrm{~mm}$. Tali pelampung mempunyai panjang $400 \mathrm{~m}$. Pelampung berbentuk bulat dan terbuat dari plastik dengan diameter $10 \mathrm{~cm}$ dan berjumlah 3.076 buah. Pemberat terbuat dari timah dan berjumlah 3.846 buah dengan bobot masing-masing $200 \mathrm{~g}$. Cincin (ring) terbuat dari timah dan berjumlah 200 buah dengan bobot masing-masing $2.000 \mathrm{~g}$. Panjang ris atas 400 $\mathrm{m}$, ris bawah $485 \mathrm{~m}$, lebar atau dalam jaring 9 pis atau $35,5 \mathrm{~m}$, dan panjang tali kolor $500 \mathrm{~m}$.

Kapal pukat cincin mini terbuat dari kayu dan mempunyai ukuran (PxLxD) antara 20,0x3,5x2,0 m$24,0 \times 4,00 \times 2,6 \mathrm{~m}$ dengan tonase antara 25-60 GT. Kekuatan mesin antara 135-320 PK dengan kecepatan 7,5-11,5 knot. Kapal pukat cincin mini mempunyai anak buah kapal 15 orang, di mana sebagian besar bertugas dalam penarikan jaring pada saat haulling. Operasi penangkapan dilakukan pada pagi hari dengan dibantu rumpon. Penurunan jaring dimulai dari sisi kiri kapal dengan kecepatan lingkar 15-20 menit. Setelah jaring melingkar, pertama-tama yang dilakukan adalah menarik tali cincin dengan menggunakan alat bantu garden. Penarikan tali cincin terlebih dahulu bertujuan agar bagian bawah jaring cepat tertutup sehingga ikan tidak keluar dari jaring. Lamanya penarikan tali cincin sekitar 20-25 menit. Setelah selesai penarikan tali cincin kemudian dilanjutkan dengan penarikan jaring. Lamanya penarikan jaring sekitar 85-95 menit. Jika penarikan jaring telah sampai pada bagian kantong tempat berkumpulnya ikan, maka kegiatan penarikan dihentikan dan dilanjutkan dengan mengambil hasil tangkapan yang kemudian dimasukkan ke dalam palkah.

Nilai CPUE pukat cincin mini berfluktuasi, dengan nilai tertinggi pada bulan Juni dan terendah pada bulan Januari (Gambar 7). Pada bulan September, produksi dan upaya penangkapan meningkat. Peningkatan ini dikarenakan pada bulan tersebut merupakan puncak musim penangkapan di sekitar perairan Laut Banda dan Sulawesi Tenggara.

Daerah penangkapan nelayan gae Kendari hampir sama dengan nelayan huhate yaitu di perairan Laut Banda dan Sulawesi Tenggara. Daerah penangkapan kapal pkat cincin mini yang berbasis di PPS Kendari disajikan pada Gambar 8.

Jenis ikan tuna hasil tangkapan pukat cincin mini yang didaratkan di PPS Kendari antara lain ikan cakalang atau skipjack-SKJ, madidihang atau yelowfin tuna-YFT, tuna mata besar atau bigeye tuna-BET, dan tongkol atau bullet tuna-BLT. Selain tuna, pukat cincin yang berbasisi di PPS Kendari juga menangkap ikan kembung, selar, sardin, dan layang. Komposisi jenis tuna yang tertangkap pukat cincin mini yang berbasis di PPS Kendari disajikan pada Gambar 9.

\section{Pancing tonda}

Pancing tonda atau troll line adalah pancing yang diberi tali panjang dan ditarik olah perahu atau kapal (Ben-Yami, 1987). Tali utama pancing tonda terbuat dari monofilamen no. 100 dengan panjang 100 depa atau sekitar $150 \mathrm{~m}$. Mata pancing yang digunakan adalah mata pancing berkait dengan no.2, 7, dan 8. Untuk mengelabui ikan digunakan umpan buatan yang dipasang pada pancing. Bahan umpan buatan adalah kain yang berwarna-warni. Jumlah pancing yang digunakan pada setiap tali utama 35 buah.

Pengoperasian pancing tonda memerlukan perahu atau kapal yang selalu bergerak di sekitar gerombolan ikan yang akan ditangkap. Kapal pancing tonda yang berada di Kendari pada umumnya berbasis di PPI Sodoha terbuat dari kayu dan mempunyai ukuran $(P x L x D)=13,0 \times 2,0 \times 1,5 \mathrm{~m}$. Mesin penggerak berkekuatan 23 PK merk Yanmar. Palkah berjumlah 3 buah dengan kapasitas masing-masing $1.500 \mathrm{~kg}$. Anak buah kapal berjumlah 5 orang yang terdiri atas kapten (nakhoda), kepala kamar mesin, dan pemancing.

Operasi penangkapan dengan menggunakan pancing tonda dilakukan pada pagi hari. Posisi pemancing berada di sisi kiri dan kanan buritan kapal. Pancing diletakkan pada kayu yang terpasang di bagian buritan kapal. Pada saat melakukan operasi penangkapan kapal tidak berhenti, namun terus berjalan mengelilingi rumpon. Operasi penangkapan tidak menggunakan umpan hidup melainkan umpan buatan. Setelah sebagian besar pancing dimakan oleh ikan, maka pancing tersebut akan ditarik dan diangkat ke atas kapal. Penarikan pancing ke atas kapal 


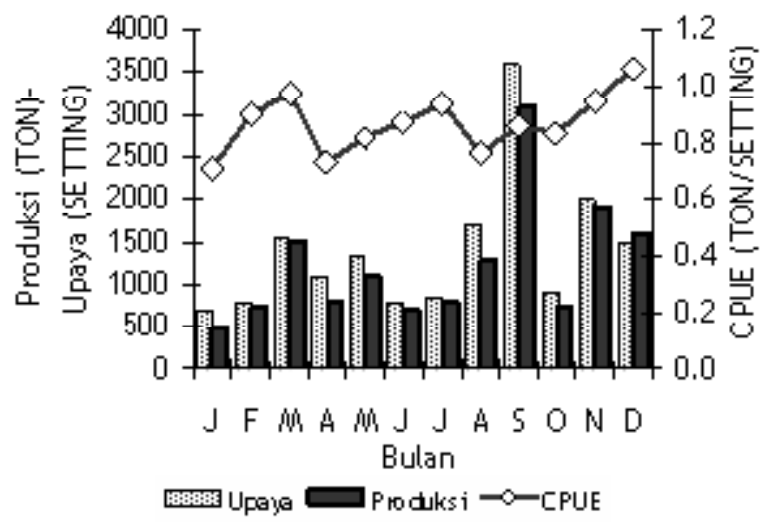

Gambar 7. Perkembangan produksi (ton), upaya penangkapan (trip) dan CPUE (ton/trip) unit penangkapan pukat cincin mini di PPS Kendari, tahun 2007.

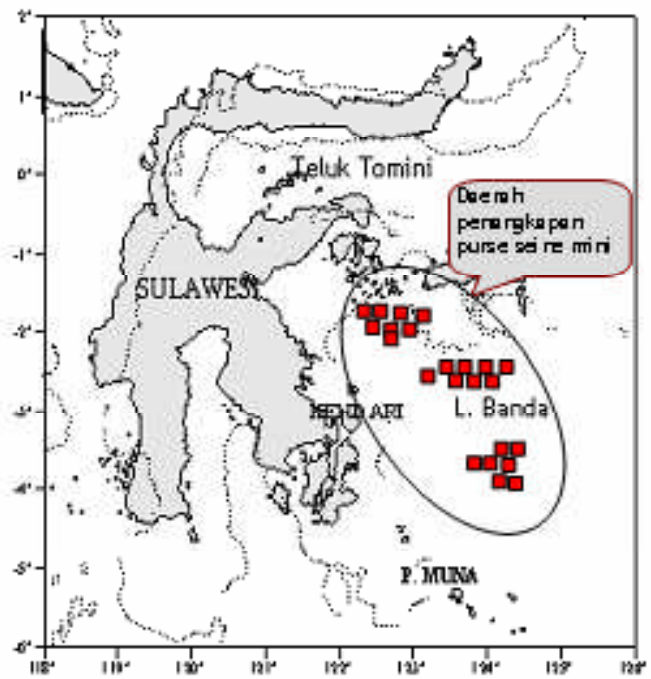

Gambar 8. Daerah penangkapan pukat cincin mini yang didaratkan di PPS Kendari.

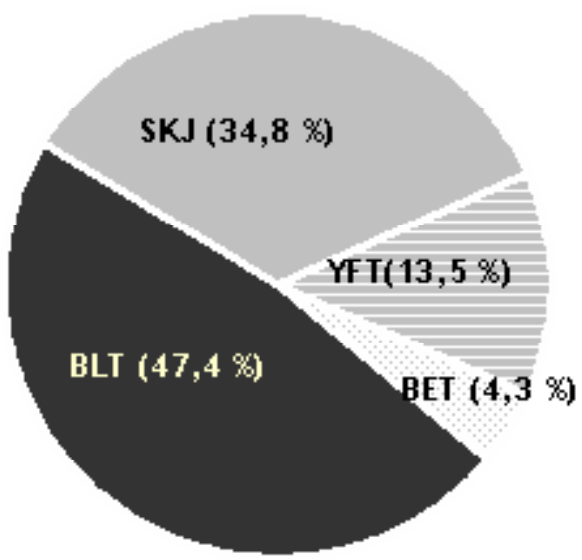

Gambar 9. Komposisi hasil tangkapan tuna yang tertangkap pukat cincin mini yang didaratkan di PPS Kendari, bulan September 2007. 
dilakukan tidak terburu-buru, hal ini dilakukan agar ikan yang sudah tertangkap tidak lepas lagi.

Selain melakukan pemancingan dengan pancing tonda, nelayan juga menggunakan layang-layang dengan umpan tiruan (cumi-cumi) untuk menangkap tuna yang berukuran besar. Pemancingan dilakukan setelah selesai melakukan pemancingan dengan pancing tonda. Tali yang digunakan terbuat dari monofilamen dan langsung diikatkan pada layanglayang. Pengoperasiannya sangat mudah, hampir sama dengan permainan layang-layang. Layanglayang yang telah diikat dengan tali diberi umpan tiruan, dan kemudian dengan bantuan angin layanglayang tersebut dilepas. Selama layang-layang ada di permukaan air, seorang pemancing terus memperhatikan ke mana perginya layang-layang tersebut sampai ada ikan yang memakan umpan tiruan tersebut.

Nilai CPUE pancing tonda berfluktuasi, dengan nilai tertinggi pada bulan September dan terendah pada bulan Juni (Gambar 10). Rendahnya nilai CPUE pada bulan Juni dikarenakan produksi dan upaya penangkapan sangat rendah, sedangkan tingginya nilai CPUE pada bulan September dikarenakan produksi meningkat dan upaya penangkapan menurun. Pada bulan September produksi dan upaya penangkapan meningkat. Hal ini dikarenakan pada bulan tersebut merupakan puncak musim penangkapan di sekitar perairan Laut Banda dan Sulawesi Tenggara. Penurunan nilai CPUE pancing tonda terjadi pada bulan Oktober-Desember. Penurunan pada bulan Oktober dikarenakan terjadinya penurunan produksi, sedangkan pada bulan Desember produksi dan upaya penangkapan menurun.

Jenis ikan tuna hasil tangkapan pancing tonda anrata lain ikan cakalang atau skipjack-SKJ, madidihang atau yelowfin tuna-YFT, tuna mata besar atau bigeye tuna-BET, dan tongkol atau bullet tuna_BLT. Komposisi hasil tangkapan pancing tonda dapat dilihat pada Gambar 11. Selain tuna, pancing tonda sering menangkap ikan lemadang (Coryphaena hippurus), layaran (Istiophorus platypterus), dan setuhuk (pada Gambar 11 diindikasikan sebagai other dengan jumlah sekitar 11,9\%).

Pancing tonda dioperasikan di sekitar rumpon, daerah penangkapan kapal pancing tonda di perairan Pulau Taliabu dan Pulau Buru disajikan pada Gambar 12

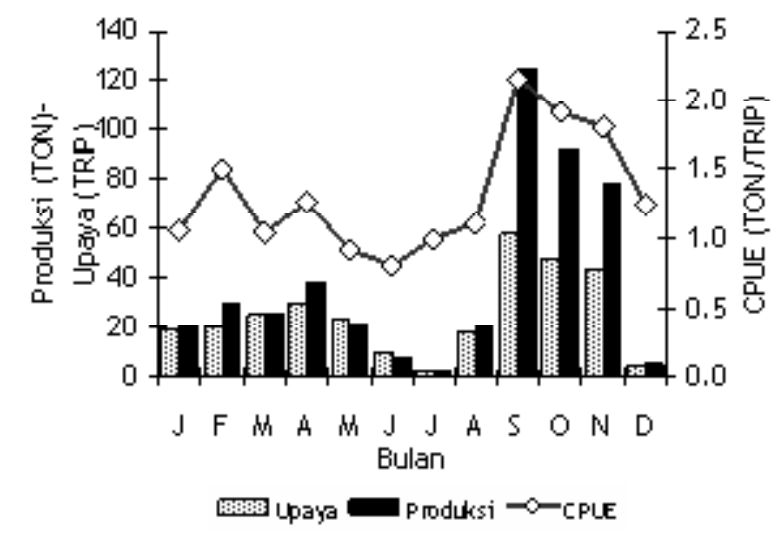

Gambar 10. Perkembangan produksi (ton), upaya penangkapan (trip) dan CPUE (ton/trip) unit penangkapan pancing tonda di PPS Kendari, tahun 2007.

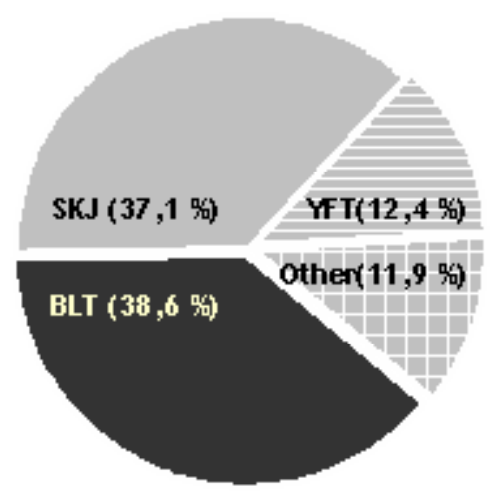

Gambar 11. Komposisi hasil tangkapan nelayan pancing tonda Kendari, bulan September 2007. 


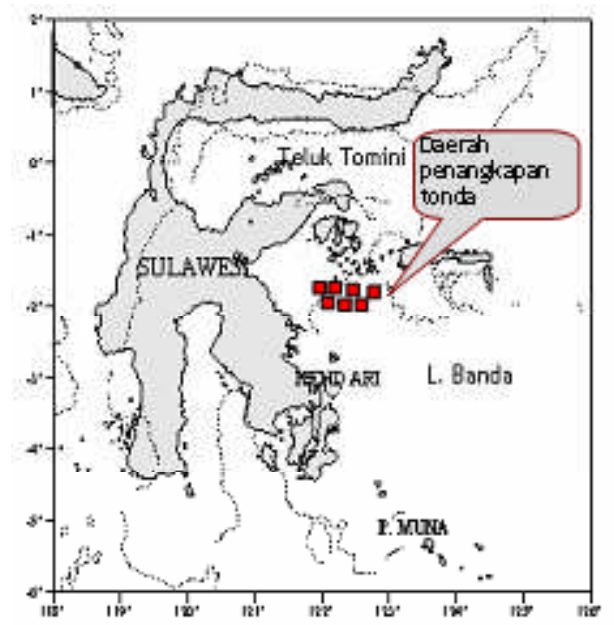

Gambar 12. Daerah penangkapan nelayan pancing tonda yang berbasis di PPS Kendari.

\section{KESIMPULAN}

1. Terdapat 3 jenis perikanan tuna yang penting yang berbasis di Kendaria yaitu huhate, pukat cincin mini, dan tonda.

2. Rata-rata CPUE huhate rata-rata 6,6 ton/trip, ratarata CPUE pukat cincin mini 0,9 ton/setting dan rata-rata CPUE pancing tonda 1,3 ton/trip.

3. Jenis tuna yang tertangkap huhate, pukat cincin mini, maupun tonda ada empat, yaitu ikan cakalang, madidihang, tuna mata besar, dan tongkol, yang didominansi oleh ikan cakalang, yaitu mencapai lebih dari $65 \%$.

4. Musim tahun 2007 terjadi pada bulan September.

\section{PERSANTUNAN}

Kegiatan dari hasil riset kelimpahan sumber daya ikan pelagis besar di perairan Laut Halmahera dan Laut Banda, T. A. 2006, di Balai Riset Perikanan LautMuara Baru, Jakarta.

\section{DAFTAR PUSTAKA}

Ben-Yami, M., 1987. Purse Seine With Small Boats. FAO. Taraining Series. FAO. Rome. 93 pp.
Diniah, M., A. Yahya, S. Pujiyati, Parwinia, S. Effendy, M. Hatta, M. Sabri, Rusyadi, \& A. Farhan. 2001. Pemanfaatan sumberd daya tuna-cakalang secara terpadu. Makalah Falsafah Sains. Program Pasca Sarjana. Institut Pertanian Bogor. Bogor.

Mertha, I. G. S., B. I. P. Santoso, \& S. Bahar. 2004. Musim Penangkapan Ikan di Indonesia. Balai Riset Perikanan Laut. Pusat Riset Perikanan Tangkap. Badan Riset Kelautan dan Perikanan. Departemen Kelautan dan Perikanan. Jakarta.

Pelabuhan Perikanan Samudera Kendari. 2008. Statistik Perikanan Pelabuhan Perikanan Samudera Kendari Tahun 2007. Direktorat Jenderal Perikanan Tangkap. Departemen Kelautan dan Perikanan.

Sainsbury, J. C. 1996. Commercial Fishing Gear: An Introduction to Vessels and Gear. $3^{\text {rd }}$. Printed and Bound by Replika Press Pvt. Ltd. India. 359 pp.

Von, B. A. 2005. Fish Catching Methods of the World. Fishing News Books Ltd. London. Forth Edition. $523 \mathrm{pp}$. 